\title{
REMOTE ESTIMATION OF WHEAT YIELD BASED ON VEGETATION INDICES DERIVED FROM TIME SERIES DATA OF LANDSAT 8 IMAGERY
}

\author{
NAQVI, S. M. Z. A. ${ }^{1}-$ TAHIR, M. N. ${ }^{*}-$ SHAH, G. A. ${ }^{1}-$ SATTAR, R. S. ${ }^{1}-$ AWAIS, M. ${ }^{2}$ \\ ${ }^{1}$ Department of Agronomy, PMAS Arid Agriculture University \\ 46300 Rawalpindi, Punjab, Pakistan \\ (e-mails: Zaigham572@gmail.com,abbaszaigham42@yahoo.com-S.M.Z.A. Naqvi; \\ shahga@uaar.edu.pk,docter_shahgee@yahoo.com-G.A.Shah) \\ ${ }^{2}$ University Institute of Biochemistry and Biotechnology, PMAS Arid Agriculture University \\ 46300 Rawalpindi, Punjab, Pakistan \\ *Corresponding author \\ e-mail: naveed@uaar.edu.pk; phone:+92-300-691-7208
}

(Received $8^{\text {th }}$ Aug 2018; accepted $31^{\text {st }}$ Oct 2018)

\begin{abstract}
Crop yield estimation prior to harvest is an important for planning and taking various policy decisions. The recent development in satellite remote sensing technologies with their increased spatial and temporal resolution enabled their enormous application for many users with low cost. The current study was planned based on time series Landsat 8 remote sensing data for real time estimation of wheat (Triticum aestivum L.) yield based on vegetation indices and ground-truthing wheat yield data for growing season 2015-16 in district Chakwal, Pakistan. Wheat yield data were collected from an area of $10 \mathrm{~m} \times 10 \mathrm{~m}$ at 43 sites along with GPS positions at farmer's field from district Chakwal to develop regressional model. Different indices like, Green Normalized Difference Vegetation Index (GNDVI), Normalized Difference Vegetation Index (NDVI), Wide Dynamic Ratio Vegetation Index (WDRVI) and Enhanced Vegetation Index (EVI) were derived from time series Landsat 8 imagery throughout the growing season (2015-16). Linear regression models fitting were developed between all the indices and ground truthing wheat yield data were analyzed based on Coefficient of Determination $\left(\mathrm{R}^{2}\right)$ and Root Mean Square Error (RMSE). The results revealed that EVI index showed higher values for the month of March 2016, compared with other months. This showed that crop was at the booting and anthesis stage in these months. The EVI and GNDVI indices showed better accuracy and precision with coefficient of determination $\left(\mathrm{R}^{2}\right) 0.89$ and 0.82 values with RMSE value of 203.83 and 224.67 respectively for the month of March-2016. This indicated that Landsat 8 imagery can be used for reliable estimation of wheat yield prior to harvest which can be useful for planning and maintaining national food security stock timely.
\end{abstract}

Keywords: remote sensing, wheat yield, time series, Landsat 8, vegetation indices

\section{Introduction}

Wheat (Triticum aestivum L.) is an important food cereal for more than $33 \%$ of the world population. Wheat yield was recorded as 754.1 million tons with production of 3.07 metric tons/ha globally which makes wheat the third most grown cereal after maize and rice (World Wheat Production, 2016). By 2050, to provide food for 900 million to 1 billion people seems to be a big challenge (Smith, 2013). Yield assessment before actual production helps in making numerous policies in agricultural production system due to high demand of food grain in the world (Sawasawa, 2003). In various countries, conventional techniques of data collection based on field visits and reports are used for crop inventory. All the rural development plans which are based on such unreliable crop acreage and production estimates become unrealistic leading to faulty decisions and 
actions and subsequent uncertainties in agricultural sector (Al-Gaadi, 2010). Remote sensing is a key component of precision agricultural practices. It is used to examine the crop growth and production and in provision rapid and nondestructive estimation of plant biomass, leaf area index (LAI), nitrogen $(\mathrm{N})$ content and grain yield (Aparicio et al., 2000; Tahir et al., 2013). Remote sensing provides a better option for precision agriculture like providing low cost data, high spectral, spatial and temporal resolution. Remote sensing works collectively with technologies of Geographic Information System (GIS), Global Positioning system (GPS) and through integration their strengths can be fully utilized (Tayari et al., 2015).

Landsat Multispectral Scanner System (MSS), Landsat Thematic Mapper (TM), and Satellite Pour l'Observation de la Terre (SPOT) are the major satellite systems. Other systems are National Oceanic and Atmospheric Administration (NOAA), Advanced Very High Resolution Radiometer (AVHRR). Early work with these satellite imagery used visual interpretation for classification (Ozesmi and Bauer, 2002). Landsat 8 Operational Land Imager (OLI) sensor has improved abilities to investigate land surface observations by adding new spectral bands of blue and cirrus cloud-detection spectrum, two improved thermal bands which includes narrower near-infrared waveband, higher signal-to-noise ratio (SNR), and better radiometric sensitivity (Roy et al., 2014; Ke et al., 2015). Spectral vegetation indices are numeric transformations of mathematical models by using different spectral bands which measures seasonal variations of vegetation, but across space as well. Hence, these are appropriate in detecting withinfield spatial variations (Viña et al., 2011). However, most vegetation indices tend to be species specific. They can recognize and provide material on spatial variation and allow more proficiency and accuracy in field investigation (Schuler, 2002). Remote sensing data in the visible, near and thermal infrared spectral bands had been used in monitoring phenology and infer biophysical variables of canopy (Rodriguez et al., 2004).

Previous researches demonstrated the utility of remote sensing but there are many areas of possible application which are still unexplored. This system is quite reliable and comprehensive and also cost effectiveness. Improvements in the accuracy and timeliness of crop production statistics are still in business. There is still lack of accurate, rapid and need practical methodologies to estimate yield of ground area. Therefore, the current study was planned to evaluate different spectral vegetation indices for accurately estimation of yield based on time series LANDSAT8 imagery data in Chakwal district. The main objectives of study were to: 1) real time (nondestructive) estimation of wheat yield based on spectral vegetation indices derived for time series Landsat 8 imagery, 2) compare the vegetation indices derived from Landsat 8 imagery with ground truthing data for developing regressional model and validation to improve the prediction accuracy of wheat yield in district Chakwal.

\section{Review of literature}

Hooda et al. (2006) observed that increasing the sample segments and decreasing the size of segments improved the area and production estimates by gradually decreasing the size of various districts. From last 15 years, the satellite data's spatial resolution has gradually improved. Moreover, improvement in the spatial, spectral and temporal resolution has extremely enhanced the capabilities to discriminate of crop from other vegetation. Since all the era the accuracy and the precision of estimation enhanced its efficiency. However, better accuracy and precision has been shown in large areas of the 
crop as compared to the areas with numerous mixed cropping systems. Presently remote sensing technique with $95 \%$ efficiency and precision enabled the acreage and yield estimation at district level.

There are many other indices that could assist in vegetation sensitivity rather than frequently used VIs in archeological investigation i.e. NDVI, SR etc. Results proved the efficiency of hyperspectral VIs by maximizing differences among archaeological and non-archaeological areas. These differences can be maximized by using narrowband indices up to $20 \%$ than broadband indices. In this study SARVI, SR and PVI are reported as most auspicious vegetation indices of broadband. SR-MTCI, SR-SR and VOG are reported as narrowband indices. Each phenological stage has different vegetation index to enhance the archaeological area than non-archaeological area (Agapiou et al., 2012).

NDVI, SM, ST and RF reported as the key factors or variables that control normal crop production. This approach might be utilized for estimation the gaps in crop produce by bringing empirical equations in use. Factors such as pests, diseases and human activities observed as the main factors of subsistence variabilities of yield estimation, which act as limiting factor in estimation techniques. Though, if NDVI is added to model which may help in determining yield losses caused by diseases or pests. The model can be calibrated by gaining more historical data of growth for the better prediction (Prasad et al., 2006).

Dempewolf et al. (2014) in his experiment evaluated four different indices, among them more consistent and more accurate yield prediction was observed by WDRVI as compared to the NDVI, EVI2 and SANDVI. While using the six years' data at district level RMSE values were found to be very low (within $0.2 \%$ and $11.5 \%$ ) among the forecast and the recorded yield. Results reported that deviations in wheat area and yield prediction were slightly higher than the previous year's moving average values. The reason behind is that 250-m MODIS data is not able to provide the sufficient spatial resolution for improved wheat area and the yield estimation.

Castaldi et al. (2015) in his introductory investigation reported vegetation variables which were gained from the SPOT data (LAI, Fcover, FAPAR, and Cab) had accurate simple and the spatial significance related to final yield of wheat on stem elongation stage. The model for the yield estimation expressed the maximum RMSE when CR models were used. Moreover, when wheat crop production mapped it aided farmers in obtaining the estimate for the crop yield and identifying variability in the field as well. This approach is best suitable to several crops as well as for several regions. It could also be observed a valued practice particularly in the conditions where limited mapping techniques of yield are present for farmers. These tools can also be utilized for the environmental changes and have ability to give the significant information for the ecological remote sensing.

\section{Materials and methods}

\section{Study area and ground truthing data collection}

The proposed study was carried out in the Chakwal district of Pakistan. District Chakwal lies at $33^{\circ} 40^{\prime}$ North and $72^{\circ} 51^{\prime}$ ' East with elevation range from 500 to $1200 \mathrm{~m}$. Total area of Chakwal is $6,524 \mathrm{~km}^{2}$. District Chakwal has population 1083725 and about $70 \%$ people's livelihood depends on agriculture directly and indirectly. The district Chakwal has temperate climate with semi-arid area and annual rainfall ranged 
from $400 \mathrm{~mm}$ to $600 \mathrm{~mm}$. It has hot summer and cold winter season. Total area depends on rain fall for agriculture. No irrigation system is present in this Area. Wheat crop usually planted in mid-November to end of November in districts Chakwal and Rawalpindi. The wheat crop has main distinct growth stages, like tillering, jointing, booting, anthesis, grain filling and physiological maturity. The March was the peak growth month of wheat crop. Wheat crop is usually harvested in end of April to midMay. Chakwal district comprises of four Tehsil and total 68 union councils. We collected the data from different locations in district Chakwal t (Fig. 1). We collected the information about crop history and then collected the wheat yield samples from farmer's field during 2015-16 growing season. Wheat yield data was collected manually from an area of $10 \times 10 \mathrm{~m}$ in the farmer's field, then expressed this yield in $\mathrm{Kg} / \mathrm{ha}$. We also took the GPS data with the help of GPS meter from the same place of wheat yield samples collected at selected sites in district Chakwal.

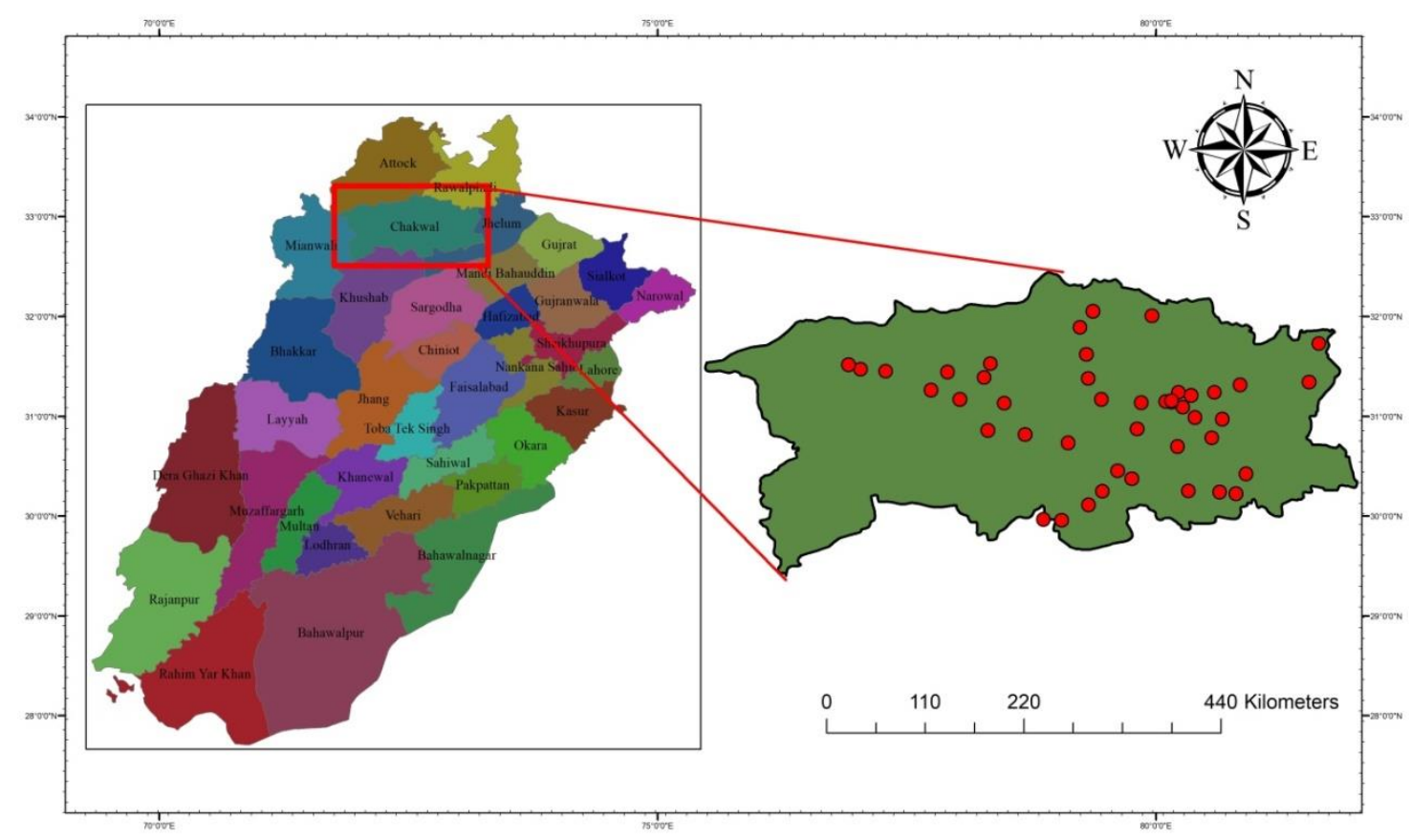

Figure 1. Map of study area of Chakwal

\section{Remote sensing data and digital image processing and analysis}

The remote sensing data was downloaded from USGS website (http://earthexplorer.usgs.gov/). We used the time series LANDSAT 8 satellite images for remote sensing data for the growing season 2015-16. Landsat 8 has 11 bands. Landsat 8 has operational land imager (OLI) and thermal infrared sensors (TIRS) with nine spectral bands with a spatial resolution of $30 \mathrm{~m}$. The bands 1 to 7 having different wavelengths with red, green and blue sensors are combined to produce true-color image. The band 8 has $15-\mathrm{m}$ resolution. The New band 9 (ultra-blue) is useful for cloud detection and also useful for costal and aerosol studies. Band 10 and 11 are thermal bands which are useful in providing more accurate surface temperature with resolution of $100 \mathrm{~m}$. 
After collecting time series images from available sources, the images were passed through different analysis processes. ERDAS IMAGINE (2014) and Arc GIS 10.2 software were used for processing and analysis of remote sensing data. The images of the study area pertaining to specific orbit, path and row were downloaded and opened into the viewer of ERDAS IMAGINE (2014). Later, geometric correction of the images was performed. Magnification of the original images was done to obtain the detailed information about the spectral reflectance of the area of interest. Images were atmospherically and geo-corrected using these ground control positions (GCPs). Stacking was performed by using Arc GIS 10.2 software. We performed the unsupervised classification by using ERDAS Imagine software. Following vegetation indices were performed on the processed images for the estimation of wheat yield by using ERDAS IMAGINE (2014) and Arc GIS 10.2 software (Fig. 2).

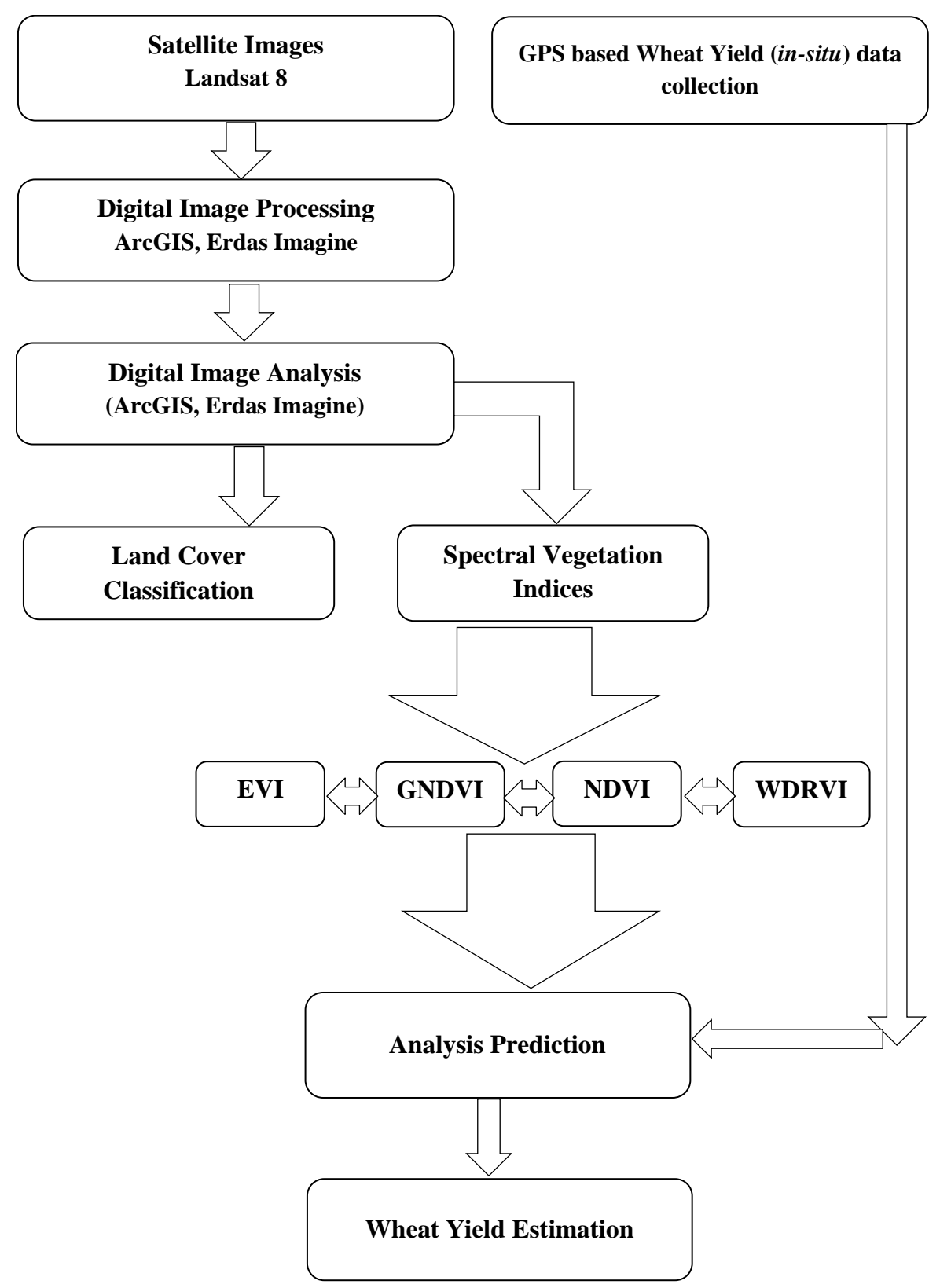

Figure 2. Flow diagram of remote estimation of wheat yield 


\section{Spectral vegetation indices}

The spectral vegetation indices are presented in Table 1.

Table 1. Spectral vegetation indices

\begin{tabular}{c|c|c|c}
\hline Sr.\# & Vegetation indices & Formula & References \\
\hline 1 & $\begin{array}{c}\text { Green normalized difference } \\
\text { vegetation index (GNDVI) }\end{array}$ & GNDVI $=\frac{(N I R-G R E E N)}{(N I R+G R E E N)}$ & $\begin{array}{c}\text { Huete et al. (2002), Wang } \\
\text { et al. (2007) }\end{array}$ \\
\hline 2 & $\begin{array}{c}\text { Normalized difference vegetation } \\
\text { index (NDVI) }\end{array}$ & $N D V I=\frac{N I R-R}{N I R+R}$ & Ferencz et al. (2004) \\
\hline 3 & Enhanced vegetation index (EVI) & EVI=2.5 $\frac{\text { NIR-RED }}{(\text { NIR+6RED-7.5BLUE)+1 }}$ & Glenn et al. (2008) \\
\hline 4 & $\begin{array}{c}\text { Wide dynamic range vegetation } \\
\text { index (WDRVI) }\end{array}$ & WDRVI $=\frac{0.1 \mathrm{NIR-RED}}{0.1 \mathrm{NIR}+\mathrm{RED}}$ & Henebry et al. (2004) \\
\hline
\end{tabular}

\section{Statistical analysis}

Regression was used to describe the effect of independent variables on dependent variable by representing the latter as a function of a former. Linear regression model were performed between satellite derived spectral vegetation indices and ground truthing yield data of wheat crop in Chakwal district. The performance of the model was estimated by comparing the differences in coefficient of determination $\left(\mathrm{R}^{2}\right)$ and root mean square error (RMSE) in prediction. The higher the $\mathrm{R}^{2}$ and the lower the RMSE value and the higher will be the precision and accuracy of model for prediction. The RMSE was calculated using following equation:

$$
R M S E=\left[\frac{1}{n} \sum_{i=1}^{n}(S i-M i)^{2}\right]^{\frac{1}{2}}
$$

\section{Results}

\section{Vegetation indices}

Following full processing of the LANDSAT 8 time series imagery for different vegetation indices were calculated using the mean values of the reflectance in green, red and NIR portion of the electromagnetic spectrum. The derived vegetation indices; GNDVI, NDVI, WDRVI and EVI proposed band ratios demonstrated the feasibility of estimating the wheat yield throughout the growing season of 2015-16. All vegetation indices for each month were used for the simple regression analysis which was performed on the field yield data to calculate equations for predicting wheat production.

\section{GNDVI yield maps derived from time series data of Landsat 8 (2015-16)}

Green normalized difference vegetation index is used for measurement of greenness in crops. The progressive increased in the GNDVI value was shown in the maps as the change in vegetation was occurred over time (Fig. 3). The GNDVI maps showed the 
variations across the Chakwal district with minimum values $(-0.1888-0.2154)$ in the month of November-2015 when crop was at early stage or in some areas at two to three leaf stage while the highest values $(-0.0806-0.36672)$ were shown in the month of March-2016 (Fig. 3). Legends indicated in maps of GNDVI represented with low to high crop vegetation in these areas.
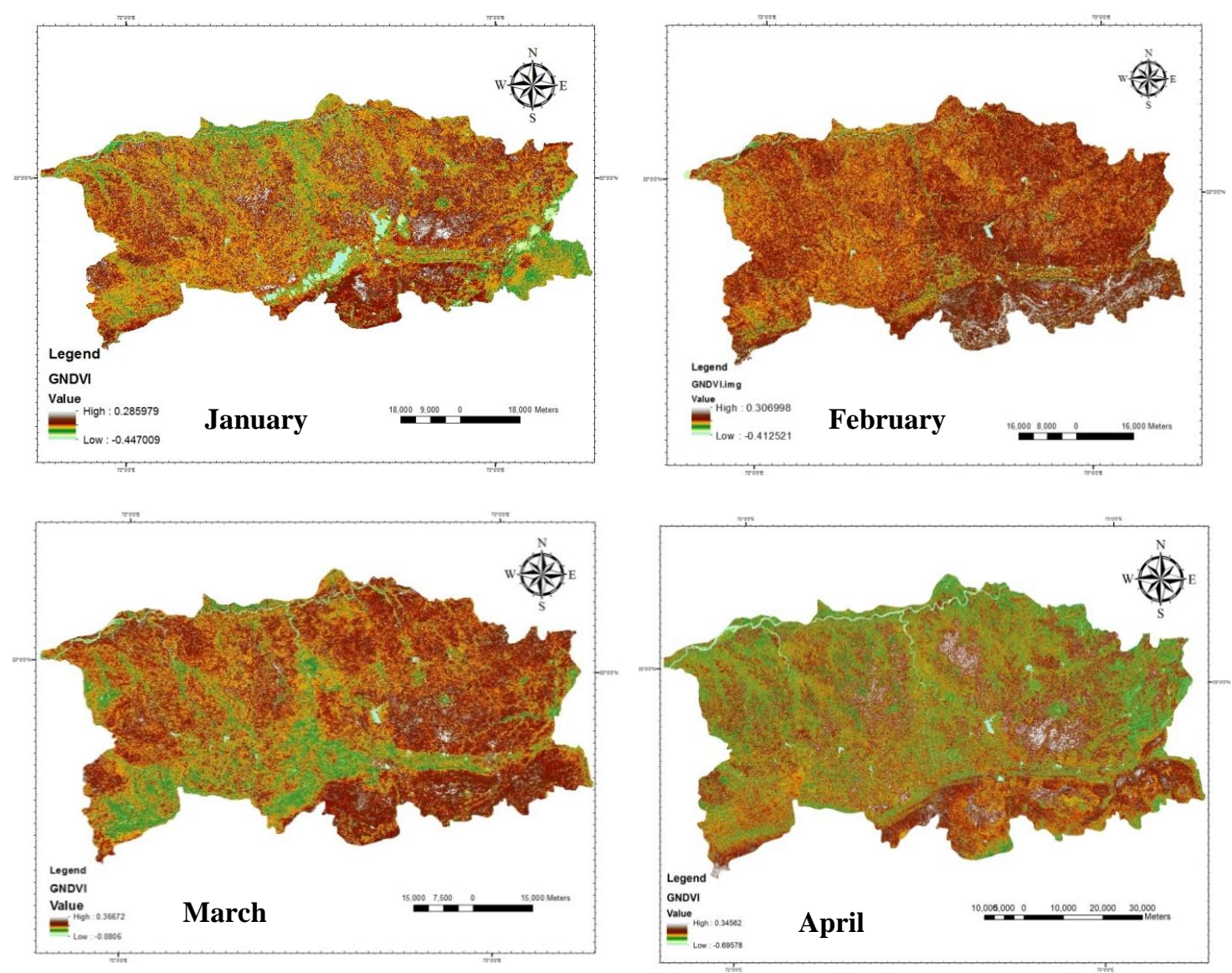

Figure 3. GNDVI map of district Chakwal during wheat growing season of 2015-16

\section{Relationship between GNDVI derived from time series Landsat 8 with ground truthing wheat yield data}

Figure 4 of wheat crop for growing season 2015-16 showed positive and strong relationship between GNDVI and wheat yield. The regressional model for each month expressed the relationship between GNDVI and wheat yield over time. A significant linear and positive relationship was observed between GNDVI and wheat yield for the month of March-2016 with coefficient of determination $\mathrm{R}^{2}=0.82$ value as compared to other months throughout the growing season which showed the highest vegetation content/cover of the wheat crop in this month. GNDVI showed great variation from November-2015 to April-2016 with coefficient determination values $\left(R^{2}\right) 0.37,0.48$, $0.61,0.72,0.82$ and 0.55 respectively. GNDVI showed the higher accuracy for predicting wheat yield accurately with the value of $\mathrm{R}^{2}=0.82$ and $\mathrm{RMSE}=224.67$ for the month of March-2016. 

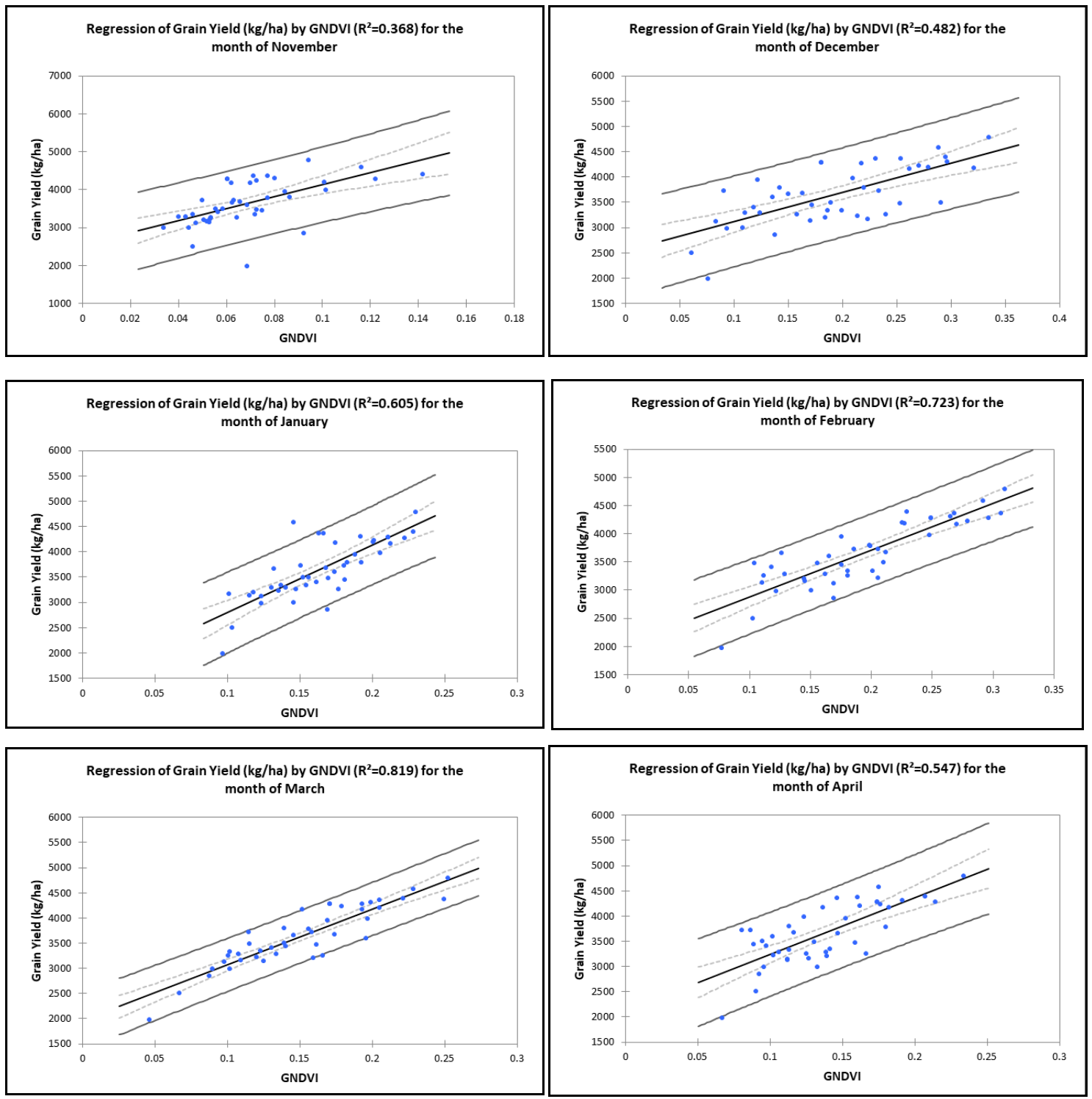

Figure 4. Relationship between GNDVI and ground truthing wheat yield throughout the growing season

\section{NDVI yield maps derived from time series data of Landsat 8 (2015-16)}

The NDVI map showed the status of whole growing season of wheat crop in district Chakwal. NDVI value ranged between -0.2538 to 0.40236 for the month of March-2016 while in the month of November-2015, NDVI value ranged between -0.1885 to 0.23224 (Fig. 5). This showed that highest crop vegetation was present in month of March-2016 and the lowest value was present in the month of November-2015. This showed that the vegetation was sparsely covered the ground during the month of November-2015. Water bodies and build area have negative value where as barren and rocks have zero value. Where as strong positive value represented only high dense green vegetative area. 

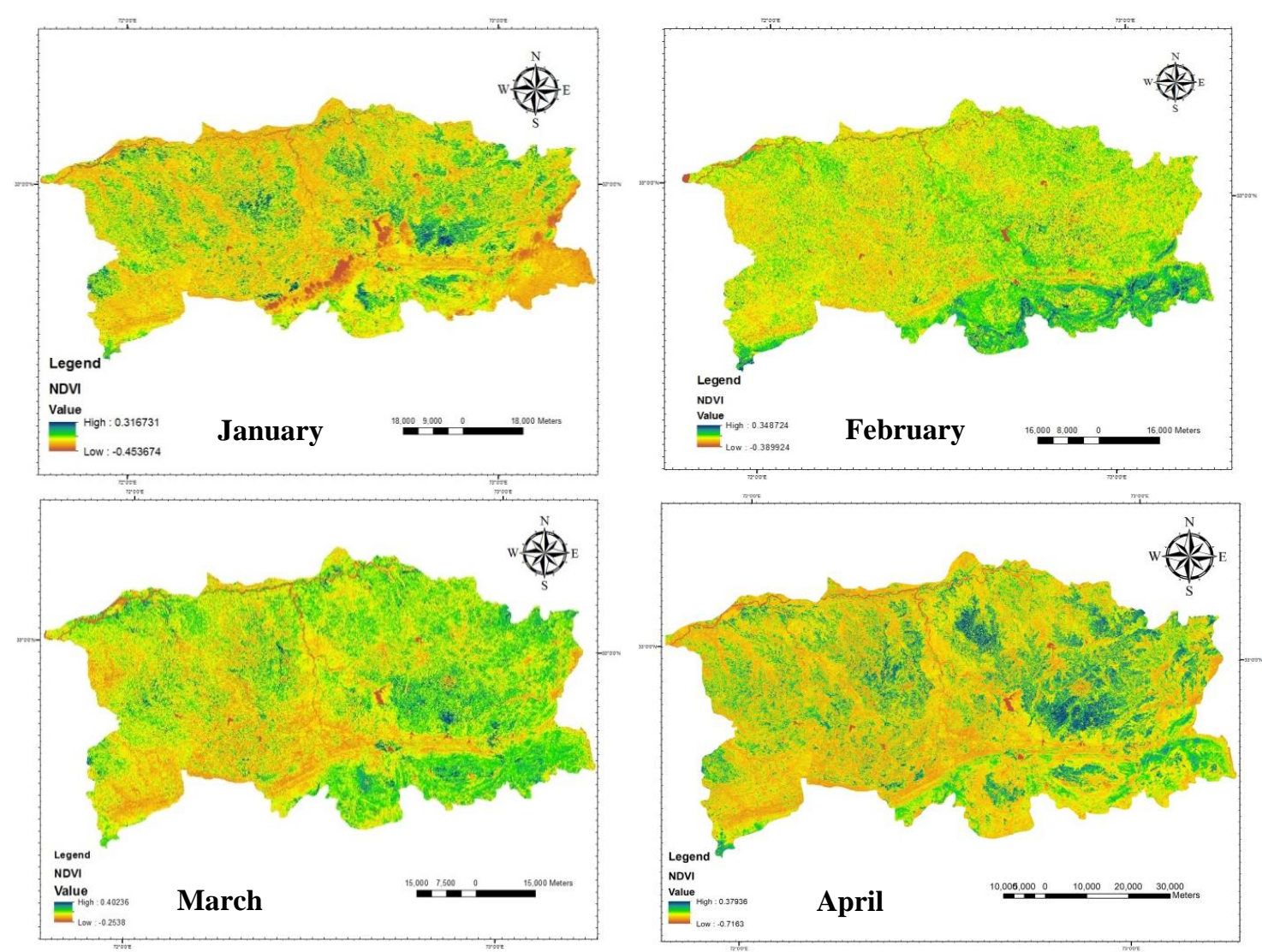

Figure 5. NDVI map of district Chakwal during wheat growing season of 2015-16

\section{Relationship between NDVI derived from time series Landsat 8 with ground truthing wheat yield data}

Figure 6 showed the significant relationship between NDVI and wheat yield throughout the growing season 2015-16. There was positive and linear relationship between NDVI and wheat yield and the regression accounted for $75 \%$ of the variation in the data $\left(R^{2}=0.75\right)$ for month of March-2016. The higher value of $R^{2}$ between the NDVI and wheat yield explained the vegetation conditions. Figure 8 showed the relationship between NDVI and high vegetation.

If $\alpha=1$, then the WDRVI is equivalent to the NDVI. By calculating the value in current study $\alpha$ was also equal to 1 . Maps of WDRVI are shown in Figure 7 . The value of WDRVI was same as NDVI for all the months. So the NDVI and WDRVI produced exactly the same results for March-2016. WDRVI showed higher value of $R^{2}=0.75$ for month of March-2016, while November showed the weak relationship with $\mathrm{R}^{2}=0.36$ (Fig. 8).

\section{EVI yield maps derived from time series data of Landsat 8 (2015-16)}

The EVI maps showed the variations across the district Chakwal. EVI wheat yield map showed great variations throughout the growing season. The highest value was shown in the month of March-2016 with the value ranged from -0.913381 to 0.903439 while the lowest value was shown in the month of November-2015 (-0.08294-0.27622). The highest value showed the highest greenness content of wheat crop (Booting and 
anthesis stage) in this month. The lowest value showed that crop was at 2-3 leaves stage and ground cover was not fully covered with the crop at this stage (Fig. 9). Legends indicated in maps of EVI represented with low to high value of crop vegetation in these areas.
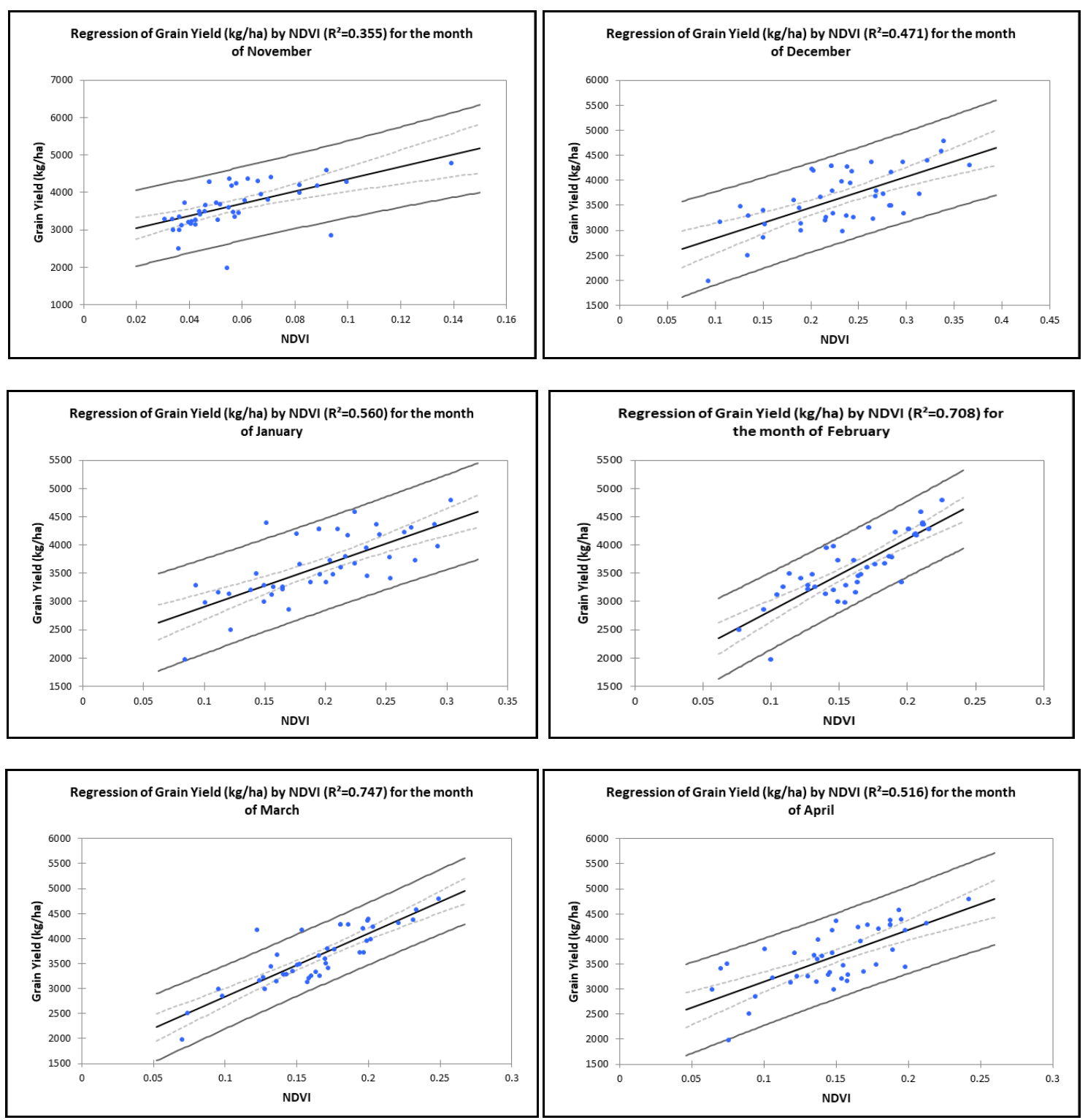

Figure 6. Relationship between NDVI and ground truthing wheat yield throughout the growing season

\section{Relationship between EVI derived from time series Landsat 8 with ground truthing wheat yield data}

Figure 10 showed very significant interactions between EVI and wheat yield. The regressional model for each month interprets the relationship between EVI and wheat yield production (Fig. 10). There was a positive and strong linear relationship between EVI and wheat yield in the month of March-2016 as compared to other months throughout the growing season of wheat crop. Minimum value of coefficient of 
determination was $\mathrm{R}^{2}=0.39$ in the month of November when crop was at emergence stage or in some areas at two or three leaf stage while the maximum value of $R^{2}=0.89$ was in the month of March where highest vegetation was present. As soon as the crop turned to yellow in most areas the EVI value also reduced to $R^{2}=0.65$ in the month of April-2016. The EVI showed the higher accuracy for predicting wheat yield for month of March-2016 with value of $\mathrm{R}^{2}=0.89$ and RMSE 203.83. Results revealed that EVI has highest efficiency to predict wheat yield than other indices used in the current study.
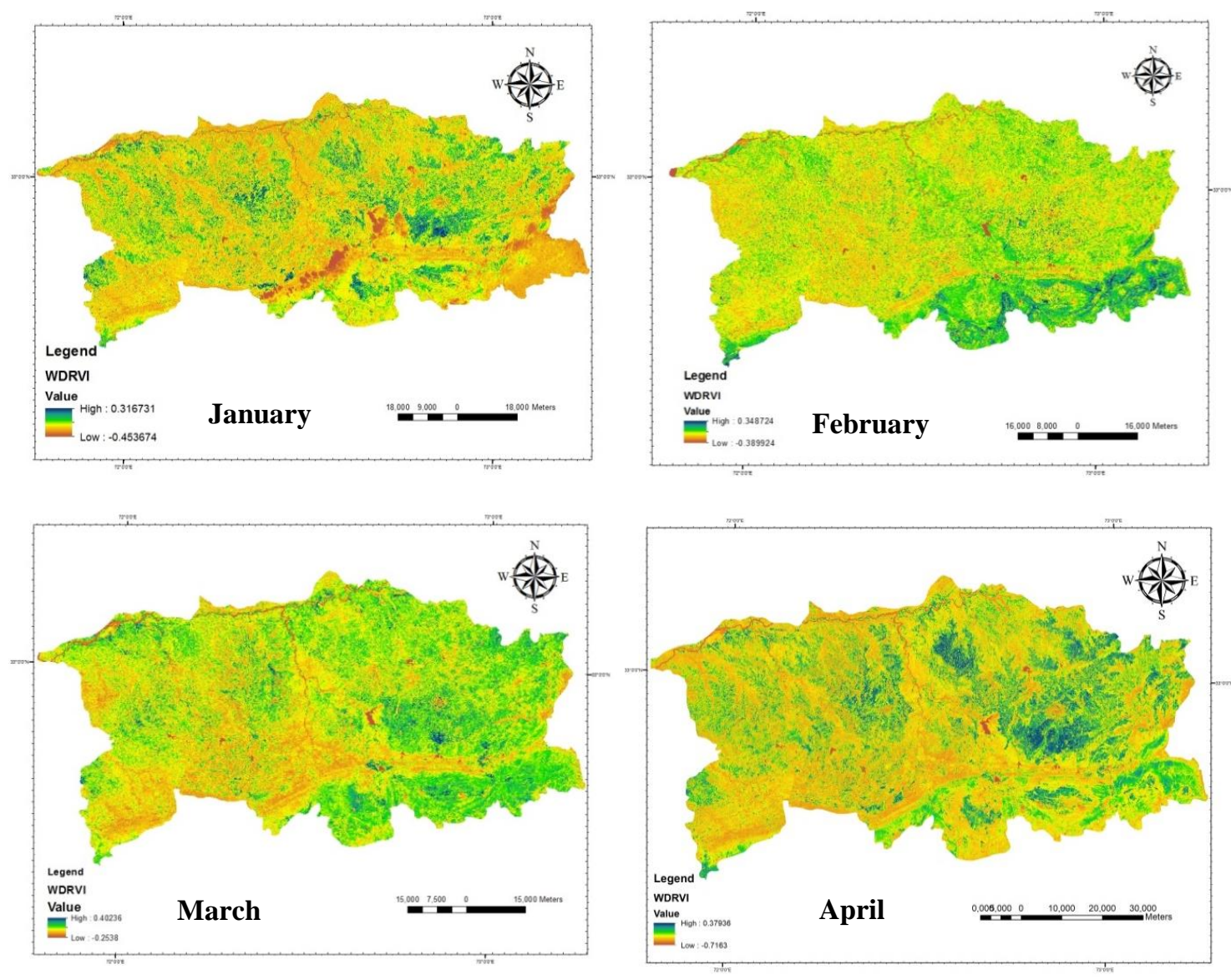

Figure 7. WDRVI map of district Chakwal during wheat growing season of 2015-16
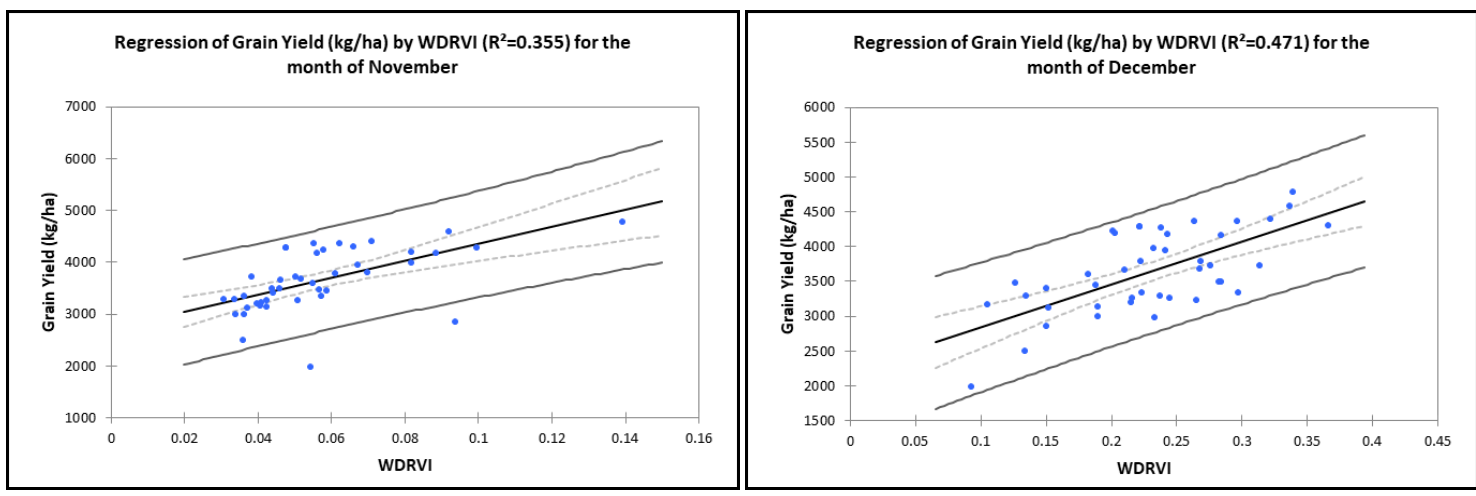

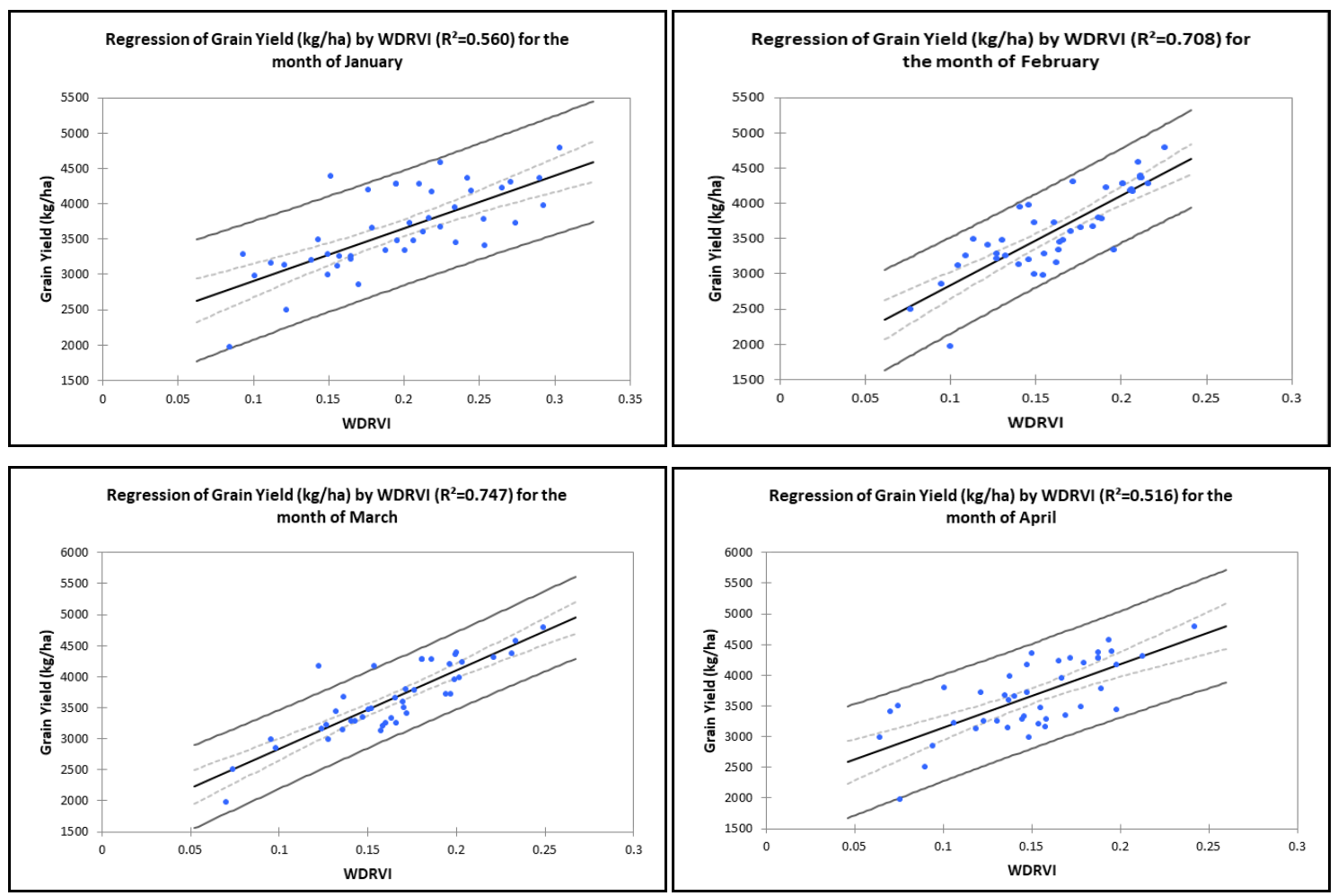

Figure 8. Relationship between WDRVI and ground truthing wheat yield throughout the growing season
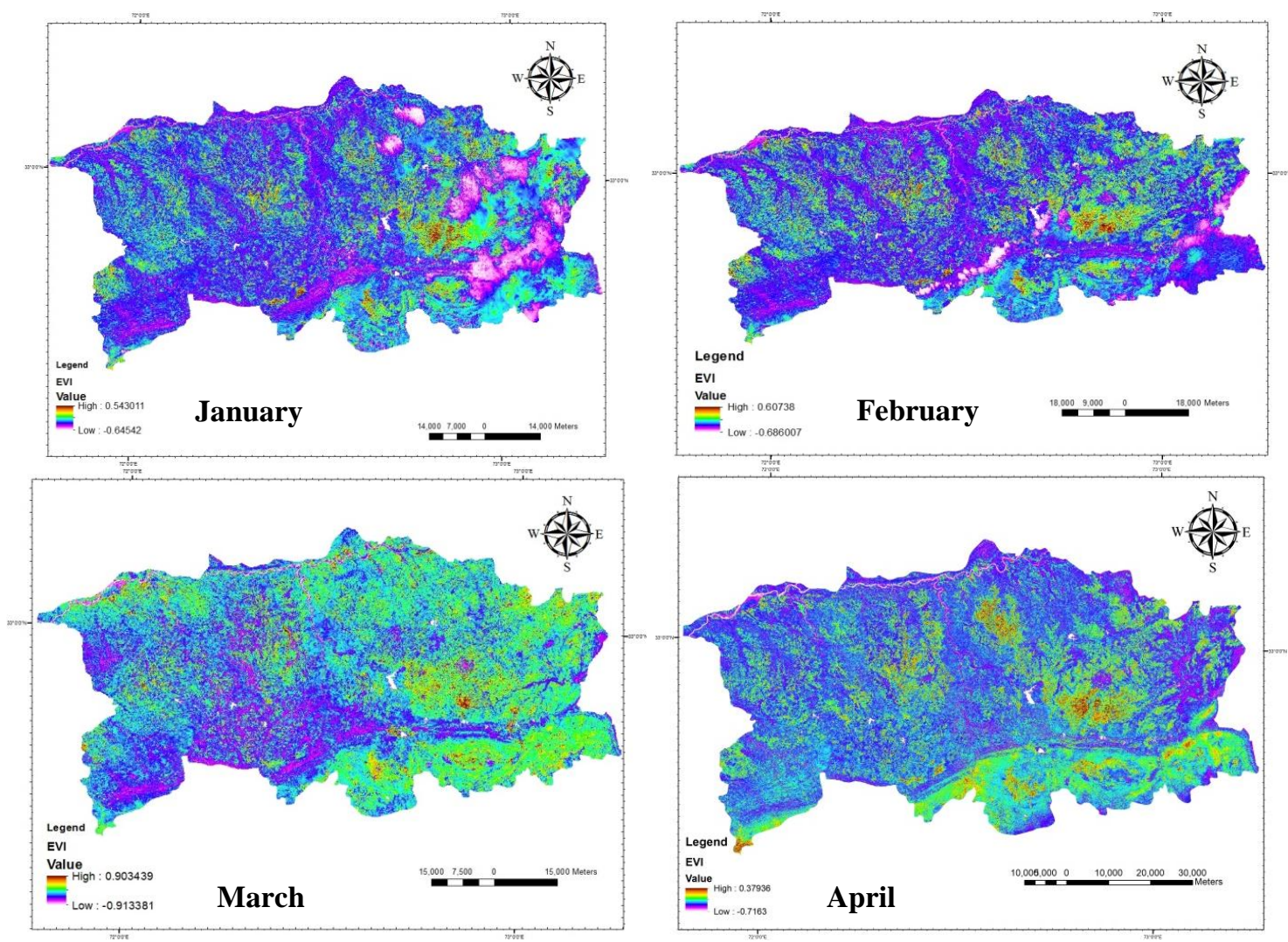

Figure 9. EVI map of district Chakwal during wheat growing season of 2015-16 

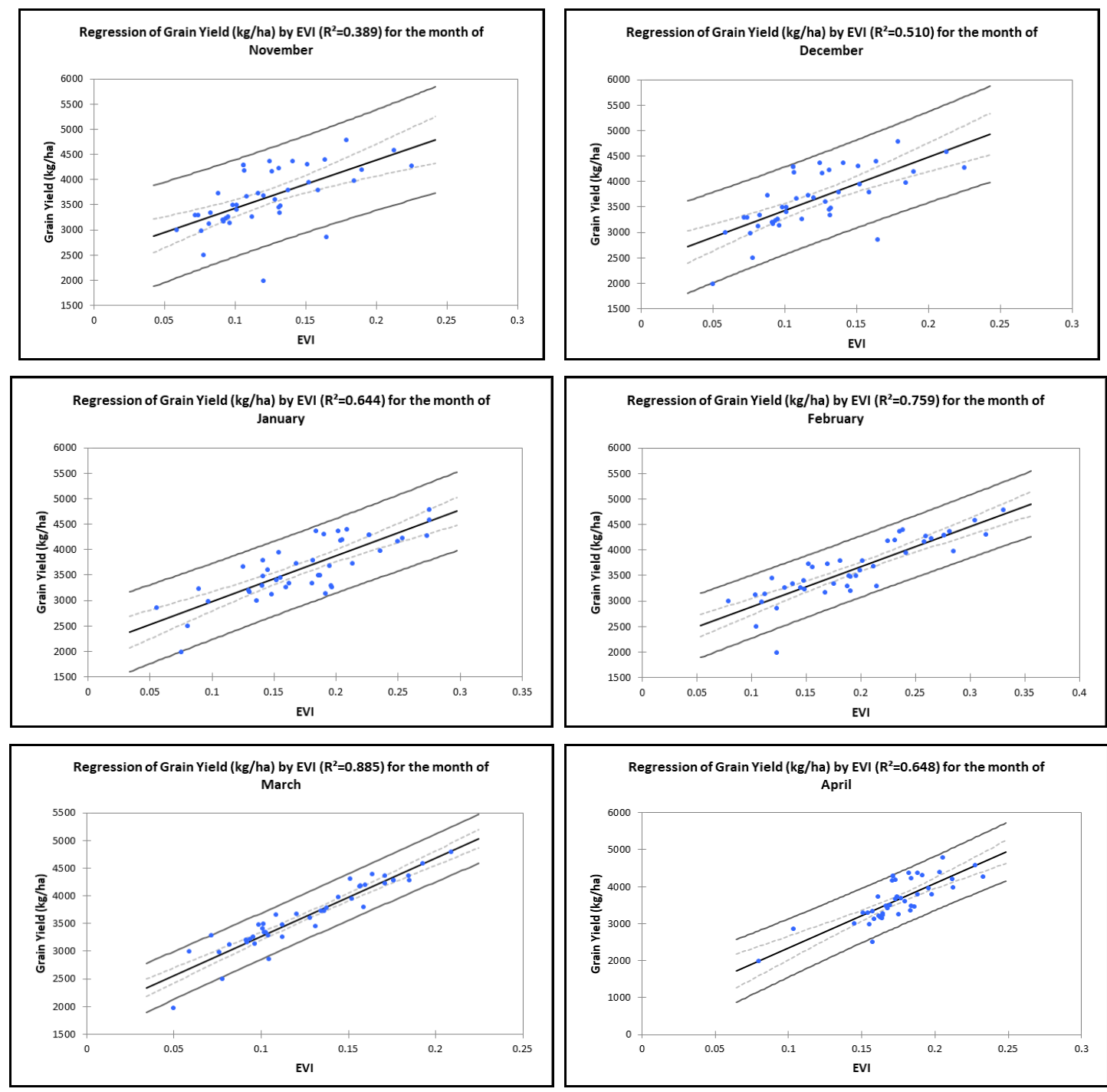

Figure 10. Relationship between EVI and ground truthing wheat yield throughout the growing season

\section{Probability map of yield}

The Probability Map of wheat yield showed the status of yield in the district Chakwal. The probability map of wheat yield was developed based on the satellite derived yield to predict the yield for the future year 2017-18. The values of probability map ranged from 1981 to $4778 \mathrm{Kg} / \mathrm{ha}$. Some areas showed with white color in map had low wheat yield with the lower value of $1981 \mathrm{Kg} / \mathrm{ha}$ in district Chakwal. When more values lied near to $4778 \mathrm{Kg} / \mathrm{ha}$ showed higher wheat yield in that part of the map as represented in blue color in the map. From map, trend of future wheat yield is shown approximately from lower to high wheat yield (Fig. 11).

\section{Discussion}

Due to advancement in satellite remote sensing technologies reduced the cost of the imageries with improved temporal and spatial resolution which improved the crop area 
and yield estimation reliable. The study was planned based on Landsat 8 time series remote sensing data to derive vegetation indices and compared with observed wheat yield data using regressional model to estimate wheat yield accurately. All vegetation indices GNDVI, NDVI, WDRVI, and EVI were derived from November 2015 to April 2016 during the whole wheat growth season. Map of all indices developed using ERADAS 14.0. February and March 2016 months were the peak wheat growing months. The Map of all indices showed higher value for the month of February and March 2016 compared with other months. This explained that crop was at booting/anthesis stages. In district Chakwal, the weather remained mild and cold till the end of March. Therefore, all indices showed higher value for the month of March 2016. Lower values of all vegetation indices showed that wheat crop was at early stage or ground cover was not fully cover by the wheat crop (Viña et al., 2011). Wheat crop was harvested from selected sites in district Chakwal during mid-April to end of May 2016.

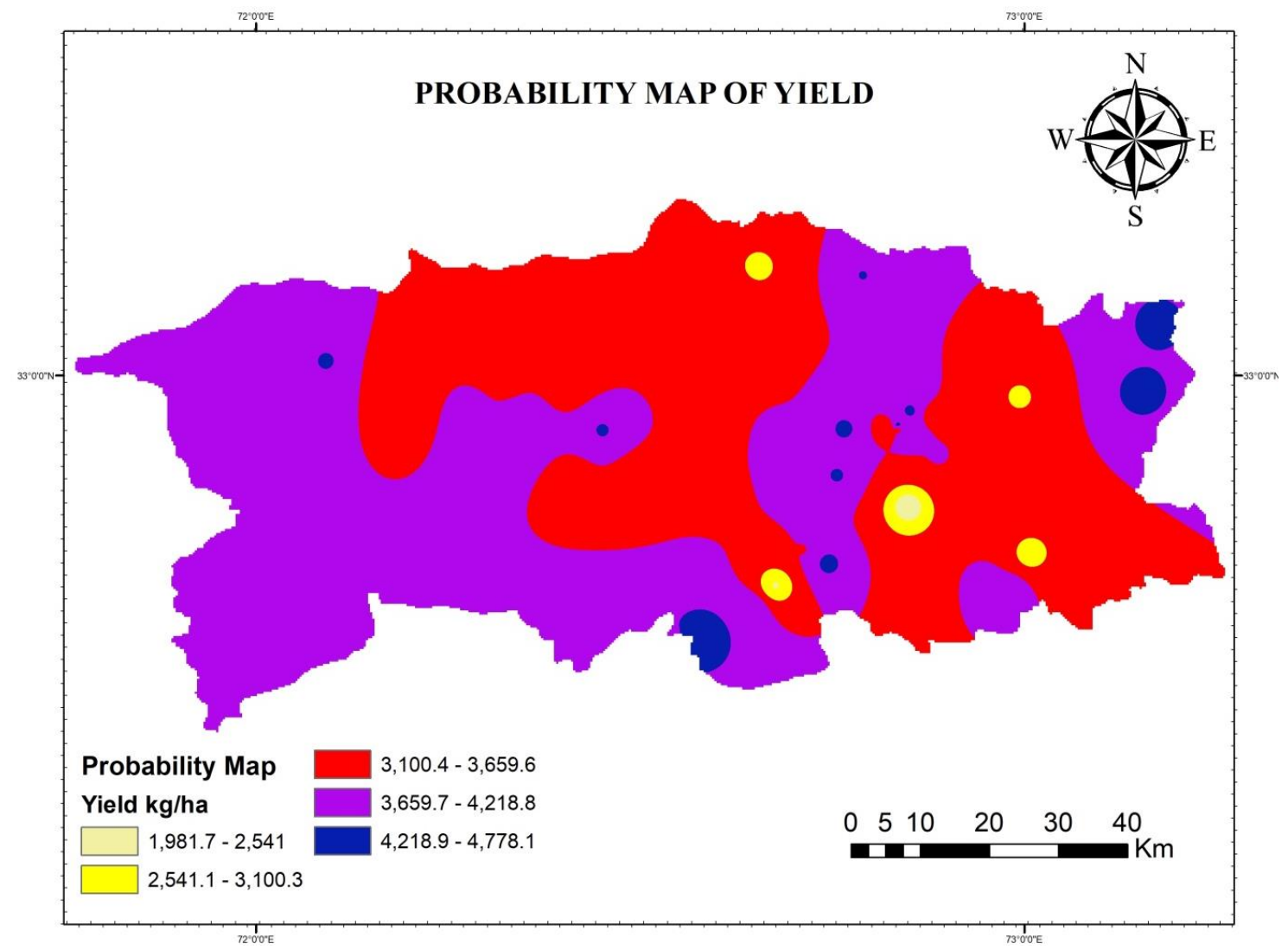

Figure 11. Probability map of district Chakwal of wheat yield

Regressional model were developed between Landsat 8 derived vegetation indices and observed wheat yield in district Chakwal for predicting wheat yield accurately. EVI and GNDVI proved more robust indices compared with NDVI and WDRVI. EVI showed positive and strong relationship with coefficient of determination value 0.89 for the month of March 2016. This is also explained that crop at booting /anthesis stage. This is the most important stage of wheat which directly related with increase of decrease crop production. The study proved that vegetation indices are robust in 
estimating wheat yield accurately. Similar results were also reported by Agapiou et al. (2012) and Shen et al. (2009, 2010).

Future wheat crop prediction was developed based on the probability analysis in ArcGIS 10.2. Remote sensing derived wheat yield were plot in district Chakwal which showed the same trend as the observed yield data collected at different sites. Results showed the improved accuracy for estimating wheat yield compared with previous studies. The current study can be helpful in future prediction of wheat yield well before time which can be useful to managing food security issues and taking better decisions for policy making.

\section{Conclusion}

Wheat yield can be achieved in real time accurately by using remote sensing data prior harvesting. Different vegetation indices were evaluated derived from time series data of Landsat 8 imagery for the growing season 2015-16. Regressional model were developed between the vegetation indices and wheat yield data for predicting wheat yield accurately. Study results showed that EVI index showed higher value for the month of February-March 2016 compared with the month of November 2015. This showed that crop was at peak vegetation stages (booting/anthesis). EVI and GNDVI proved more robust indices and showed better accuracy compared with other indices. EVI showed the higher accuracy with $\mathrm{R}^{2}=0.89$ value and RMSE value of 203.83 for determining wheat yield accurately. The current study can be helpful in future prediction of wheat yield well before time which can be useful to managing food security issues and taking better decisions for policy making.

\section{REFERENCES}

[1] Agapiou, A., Hadjimitsis, D. G., Alexakis, D. D. (2012): Evaluation of broadband and narrowband vegetation indices for the identification of archaeological crop marks. Remote sensing 4: 3892-919.

[2] Al-Gaadi, K. A. (2010): Remote sensing, geographic information system and modeling techniques for wheat area and production estimation. - Karnataka Journal of Agricultural Sciences 23: 550-3.

[3] Aparicio, N., Villegas, D., Casadesus, J., Araus, J. L., Royo, C. (2000): Spectral vegetation indices as nondestructive tools for determining durum wheat yield. Agronomy Journal 92: 83-91.

[4] Castaldi, F., Casa, R., Pelosi, F., Yang, H. (2015): Influence of acquisition time and resolution on wheat yield estimation at the field scale from canopy biophysical variables retrieved from SPOT satellite data. - International Journal of Remote Sensing 36: 243859.

[5] Dempewolf, J., Adusei, B., Becker-Reshef, I., Hansen, M., Potapov, P., Khan, A., Barker, B. (2014): Wheat yield forecasting for Punjab Province from vegetation index time series and historic crop statistics. - Remote Sensing 6: 9653-75.

[6] Ferencz, C., Bognar, P., Lichtenberger, J., Hamar, D., Tarcsai, G., Timar, G., Molnar, G., Pásztor, S., Steinbach, P., Szekely, B. (2004): Crop yield estimation by satellite remote sensing. - International Journal of Remote Sensing 25: 4113-49.

[7] Gitelson, A. A. (2004): Wide dynamic range vegetation index for remote quantification of biophysical characteristics of vegetation. - Journal of Plant Physiology 161: 165-73. 
[8] Glenn, E. P., Huete, A. R., Nagler, P. L., Nelson, S. G. (2008): Relationship between remotely-sensed vegetation indices, canopy attributes and plant physiological processes: what vegetation indices can and cannot tell us about the landscape. - Sensors 8: 2136-60.

[9] Henebry, G. M., Viña, A., Gitelson, A. A. (2004): The wide dynamic range vegetation index and its potential utility for gap analysis. - Gap Analysis Bulletin 12: 50-6.

[10] Hooda, R., Yadav, M., Kalubarme, M. (2006): Wheat production estimation using remote sensing data: An Indian experience. - Workshop Proceedings: Remote Sensing Support to Crop Yield Forecast and Area Estimates, Stresa, Italy 30 Nov-1 Dec 2006, pp. 85-9.

[11] Huete, A., Didan, K., Miura, T., Rodriguez, E. P., Gao, X., Ferreira, L. G. (2002): Overview of the radiometric and biophysical performance of the MODIS vegetation indices. - Remote Sensing of Environment 83: 195-213.

[12] Ke, Y., Im, J., Lee, J., Gong, H., Ryu, Y. (2015): Characteristics of Landsat 8 OLIderived NDVI by comparison with multiple satellite sensors and in-situ observations. Remote Sensing of Environment 164: 298-313.

[13] Ozesmi, S. L., Bauer, M. E. (2002): Satellite remote sensing of wetlands. - Wetlands Ecology and Management 10: 381-402.

[14] Prasad, A. K., Chai, L., Singh, R. P., Kafatos, M. (2006): Crop yield estimation model for Iowa using remote sensing and surface parameters. - International Journal of Applied Earth Observation and Geoinformation 8: 26-33.

[15] Rodriguez, J., Duchemin, B., Hadria, R., Watts, C., Garatuza, J., Chehbouni, A., Khabba, S., Boulet, G., Palacios, E., Lahrouni, A. (2004): Wheat yield estimation using remote sensing and the STICS model in the semiarid Yaqui valley, Mexico. - Agronomie 24: 295-304.

[16] Roy, D. P., Wulder, M., Loveland, T. R., Woodcock, C., Allen, R., Anderson, M., Helder, D., Irons, J., Johnson, D., Kennedy, R. (2014): Landsat-8: Science and product vision for terrestrial global change research. - Remote Sensing of Environment 145: 154-72.

[17] Sawasawa, H. L. (2003): Crop Yield Estimation: Integrating RS, GIS, and Management Factors. A Case Study of Birkoor and Kortigiri Mandals, Nizamabad District India. International Institute for Geo-Information Science and Earth Observation, Enschede, The Netherlands, pp. 1-9.

[18] Schuler, R. T. (2002): Remote sensing experiences in production fields. - Proceedings of the: Wisconsin Fertilizer, Aglime and Pest Management Conference. Cooperative Extension, University of Wisconsin - Extension, College of Agricultural and Life Sciences, University of Wisconsin, Madison, pp. 9653-75.

[19] Shen, M., Chen, J., Zhu, X., Tang, Y. (2009): Yellow flowers can decrease NDVI and EVI values: evidence from a field experiment in an alpine meadow. - Canadian Journal of Remote Sensing 35: 99-106.

[20] Shen, M., Chen, J., Zhu, X., Tang, Y., Chen, X. (2010): Do flowers affect biomass estimate accuracy from NDVI and EVI? - International Journal of Remote Sensing 31: 2139-49.

[21] Singh, R. (2003): Use of satellite data and farmers eye estimate for crop yield modeling. J Ind Soc Agril Statist 56: 166-76.

[22] Smith, P. (2013): Delivering food security without increasing pressure on land. - Global Food Security 2: 18-23.

[23] Tahir, M. N., Li, J., Liu, B., Zhao, G., Fuqi, Y., Chengfeng, C. (2013): Hyperspectral estimation model for nitrogen contents of summer corn leaves under rainfed conditions. Pak J Bot 45: 1623-30.

[24] Tayari, E., Jamshid, A. R., Goodarzi, H. R. (2015): Role of GPS and GIS in precision agriculture. - Journal of Scientific Research and Development 2: 157-62.

[25] Viña, A., Gitelson, A. A., Nguy-Robertson, A. L., Peng, Y. (2011): Comparison of different vegetation indices for the remote assessment of green leaf area index of crops. Remote Sensing of Environment 115: 3468-78. 
[26] Wang, F.-M., Huang, J.-F., Tang, Y.-L., Wang, X.-Z. (2007): New vegetation index and its application in estimating leaf area index of rice. - Rice Science 14: 195-203.

[27] World Wheat Production (2016): https://www.worldwheatproduction.com/. - Accessed 11 November 2017. 